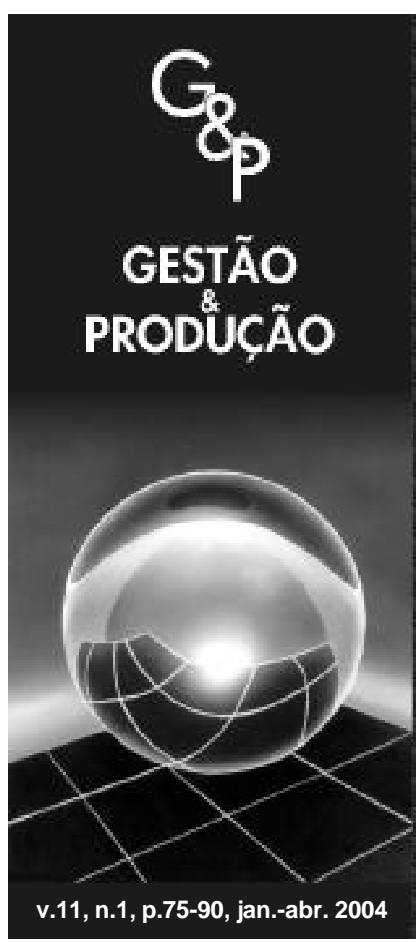

\title{
CONSTRUÇÃO DE INDICADORES PARA AVALIAÇÃO DE CONCEITOS INTANGÍVEIS EM SISTEMAS PRODUTIVOS
}

\author{
Miguel Afonso Sellitto \\ Centro de Ciências Exatas e Tecnológicas, Universidade do Vale do Rio \\ dos Sinos, Unisinos, Av. Unisinos, 950, CEP 93022-000, \\ São Leopoldo, RS, e-mail: miguelsv@terra.com.br \\ José Luis Duarte Ribeiro \\ Programa de Pós-Graduação em Engenharia de Produção, Universidade Federal \\ do Rio Grande do Sul, UFRGS, Praça Argentina, 9, sala LOPP, \\ CEP 90040-020, Porto Alegre, RS, e-mail: ribeiro@producao.ufrgs.br
}

Recebido em 16/1/2003

Aprovado em 17/2/2004

Resumo

Este trabalho apresenta o desenvolvimento e a aplicação de um método para a construção de indicadores a fim de avaliar aspectos intangíveis de um sistema produtivo. Hoje em dia, principalmente nas organizações de serviços, os aspectos intangíveis têm sido usados na modelagem do sistema, no entendimento de problemas e na proposta e implementação de estratégias. A partir da teoria das medições, que se baseia na filosofia da ciência e na estatística multivariada, foi elaborada uma abordagem para a modelagem teórica dos conceitos intangíveis de um sistema produtivo. A abordagem tem início com o mapeamento teórico das variáveis não-manifestas, e continua identificando os construtos e o estado das variáveis, que pode estar relacionado a conceitos intermediários, suportados por variáveis manifestas que podem assumir formatos categóricos, a serem pesquisadas por instrumentos apropriados, como os questionários. Após essas definições, o fenômeno em estudo pode ser representado por diagramas de caminho. Se o diagrama assume forma de árvore, a regressão múltipla pode ser usada e a análise é facilitada. Se o diagrama assume forma sistêmica, incluindo relações circulares, é necessário um tratamento matemático mais complexo, que foge do escopo deste trabalho. Uma aplicação da abordagem proposta foi conduzida em quinze empresas de transporte coletivo de Porto Alegre, sendo mensurada a capacidade das empresas de apreender os conceitos de produção enxuta. Os resultados são discutidos e são apresentadas sugestões para a continuidade dos trabalhos.

Palavras-chave: valores intangíveis, modelagem teórica, variáveis categóricas, produção enxuta.

\section{Introdução}

A discussão sobre grandezas intangíveis tem sido tema recorrente em pesquisas. Como o acesso a essas grandezas não é unívoco, o pesquisador deve identificar os conceitos a elas subjacentes, até chegar a grandezas de mensuração direta, ou, ao menos, indiretamente aferíveis. A contabilidade tem se referido a essas grandezas como ativos intangíveis. Para Speckbacher et al. (2003), é o gerenciamento desses ativos intangíveis, como a flexibilidade, o conhecimento e a inovação, que sustenta a vantagem competitiva no atual cenário industrial.
Este trabalho trata de medições de intangíveis de modo geral. Para manter certa diferenciação em relação ao campo de ação e aos métodos já propostos pela contabilidade, essas grandezas serão doravante chamadas de conceitos intangíveis. Estes, por sua vez, podem assumir papéis relevantes em sistemas de produção, principalmente no setor de serviços, influenciando o desempenho estratégico medido. Vale mencionar que toda medição de desempenho já incorpora um conceito intangível: a própria estratégia da organização.

Elementos da teoria das medições podem ser úteis na medição de conceitos intangíveis. Segundo French (1986), 
a teoria das medições (measurements theory) é um campo de conhecimentos, sediado em algum lugar entre a matemática e a filosofia da ciência, que trata de modelos numéricos capazes de estruturar descrições qualitativas de crenças ou preferências de indivíduos. Da matemática, a teoria das medições se vale de técnicas de análise multivariada e de modelagem estatística. Da filosofia da ciência, a teoria das medições requisita as técnicas de investigação sobre a causalidade entre objetos de estudo e seus antecedentes. Ao descrever um sistema em observação, a teoria das medições usa relações como: (i) para determinado fim, Aé preferível, é indiferente ou não é preferível a $\mathrm{B}$; (ii) dado que $\mathrm{A}$ é preferível a $B$, esta preferência é fraca ou estrita; ou ainda (iii) dado que Aé estritamente preferível a B, esta preferência é pequena, média ou grande. Para descrever o sistema, utilizase uma representação numérica de suas relações qualitativas, na qual a magnitude relativa dos números expressa a estrutura de preferências ou crenças de indivíduos sobre o sistema. Os números podem ser escolhidos de modo arbitrário, desde que haja uma relação racional que permita operações aritméticas dentro da estrutura de preferências. French (1986, p. 77) demonstra que é possível representar por variáveis numéricas qualquer relação qualitativa que expresse uma estrutura de preferências consistente.

A medição de desempenho estratégico requer a avaliação de conceitos intangíveis e também é tema recorrente em pesquisas. Dada a importância e a diversidade de ambos em sistemas produtivos, julgou-se oportuno investigar o tema. Assim, o objetivo deste trabalho é estruturar uma metodologia para a construção de um indicador que possa mensurar um conceito intangível relevante em um sistema produtivo. Após a estruturação teórica do método, será apresentada e discutida sua aplicação em uma indústria de serviços: o transporte coletivo de passageiros de uma capital estadual brasileira.

\section{Revisão bibliográfica}

Segue uma revisão teórica de conceitos originados nos campos de conhecimento requeridos pela teoria das medições, a filosofia da ciência e a matemática. Apresenta-se também uma breve revisão de alguns dos sistemas existentes de medição de resultados organizacionais, para que seja possível, enfim, relacioná-los com a proposta deste trabalho.

\subsection{Relações de causalidade}

Há diversas definições para ciência. Uma delas afirma que a ciência é o conjunto de conhecimentos organizados, gerados por intermédio de estudos, e cujas conclusões foram alcançadas após a investigação das relações de causa e efeito apresentadas pelos fenômenos de interesse. Os cientistas não se limitam, portanto, a descrever os fatos, mas procuram encontrar suas causas, suas relações internas e suas relações com outros fatos.
Estabelecer relacionamentos entre os fenômenos observáveis diretamente na natureza e suas causas não é novidade na história da investigação científica. Aristóteles, na Grécia antiga, dividia um objeto de estudo em duas partes: (i) seu ser, a essência do objeto; e (ii) sua qualificação, ou predicados, que mais tarde foram traduzidos como categorizações. A filosofia aristotélica usava o método da contemplação dos fenômenos para descobrir os mecanismos de governo, ou seja, as relações de causalidade. Explicava as categorizações dos objetos por meio de quatro causas: (i) causa material; (ii) causa formal; (iii) causa eficiente; e (iv) causa final. As duas primeiras diziam respeito à construção, a terceira referia-se à lei de governo e a quarta considerava o efeito do objeto (Souza Filho, 2000). Ao relacionar as leis de governança dos fenômenos com os efeitos percebidos, indicando uma circularidade no raciocínio, Aristóteles, de certo modo, já antevia uma abordagem sistêmica para o estudo da natureza.

O objeto de investigação dos filósofos gregos era o encontro de uma explicação natural para os fenômenos naturais, ou seja, a formulação de uma teoria que fizesse uma conexão causal entre os fenômenos. Para esses filósofos, explicar o fenômeno era relacionar um efeito a uma causa que o antecede e o determina, por meio de um nexo causal. A existência e o conhecimento do nexo causal tornariam a realidade inteligível e, algumas vezes, controlável. A explicação causal era regressiva, ou seja, a explicação de um fenômeno por uma causa requeria outra causa mais básica, até que se chegasse a uma situação inexplicável, que não mais contribuiria para a construção de uma teoria. Para evitar esse impasse, os filósofos gregos propuseram a noção de arquè, o elemento primordial, a partir do qual se iniciaria o processo racional de análise. Diversos elementos foram propostos como arquè, sendo que sua organização em um modo ordenado e harmonioso formaria o kosmos. O oposto do kosmos seria o kaos. O kosmos se organizaria em hierarquias, tendo a causalidade como lei principal: para conhecer as hierarquias seria necessário conhecer as leis que as governam. Em suma, as relações de causa-efeito entre os fenômenos (Souza Filho, 2000).

Francis Bacon, pensador empirista do século XVII, propôs o método das coincidências constantes. O método postula que a todo fenômeno observável corresponde uma causa necessária e suficiente: (i) surge a causa, surge o efeito; (ii) desaparece a causa, desaparece o efeito; e (iii) varia a causa, varia o efeito. A experimentação como técnica para o descobrimento das relações de causalidade também aparece em Francis Bacon. Com base em observações repetidas, seria conhecido o funcionamento dos fenômenos, permitindo que uma lei generalista surgisse. Já David Hume, empirista escocês do século XVIII, sugere que não há causas nem efeitos na natureza, mas, sim, precedências e consequiências, ou seja, é possível verificar a temporalidade dos fenômenos, mas não é possível determinar sua causa- 
lidade. Uma relação de causa e efeito seria uma mera construção da mente humana: não haveria evidência natural tangível que a justificasse. Hume propugnava que a noção de causalidade, o nexo causal, não é perceptível pelos sensos humanos, capazes de perceber no máximo uma conjunção constante entre fenômenos e não a conexão necessária, a que implica causalidade. Uma relação de causalidade seria, assim, apenas uma criação, uma forma que a mente humana usa para perceber regularidades e repetições impostas pela natureza. Portanto, para Hume, se o conhecimento provém da percepção sensitiva sobre a repetição dos fenômenos, e as percepções são suscetíveis a erros de interpretação, jamais se terá um conhecimento absoluto sobre os nexos causais, introduzindo a noção de probabilidade nas relações de causa e efeito (Souza Filho, 2000; Barros \& Lehfeld, 2000).

Em oposição ao empirismo, o racionalismo propõe que se chegue ao entendimento das causas dos fenômenos por meio da reflexão dedutiva, ou silogismo. Dadas as premissas de um fenômeno, por dedução se chega à conclusão, originalmente inserida nas premissas, mas ainda não explicitada. Chegaria-se à certeza pela razão, considerada o princípio absoluto do conhecimento humano. Expoente do racionalismo, Descartes propõe, entre outras regras de abordagem de problemas, a análise e a síntese. A análise divide uma situação em tantas partes quantas necessárias, até que se tenha um fenômeno capaz de ser entendido e explicado racionalmente. Já a síntese caminha na direção oposta: vai das partes constituintes em direção ao todo, identificando e relacionando as partes analisadas. A análise e a síntese podem operar tanto em fenômenos naturais, dividindo e identificando as partes físicas constituintes, como em fenômenos mentais, em que um conceito é dividido em conceitos subjacentes que suportam e constroem o conceito original (Lakatos \& Marconi, 1991).

O empirismo se importaria mais com as leis que governam os fenômenos, tendendo a uma abordagem quantitativa, ao passo que o racionalismo se preocuparia mais com a essência dos fenômenos, tendendo a uma abordagem qualitativa. A partir da oposição entre o empirismo e o racionalismo, e em um exercício dialético, Popper propõe o método hipotético-dedutivo para a investigação dos fenômenos. Popper parte do argumento: muitos casos positivos não garantem uma afirmação, como quer a indução, mas um único caso negativo garante a negação. Para solucionar um problema, Popper parte de uma construção racional, que não pode ser testada. Se o componente primário da construção for verdadeiro, além do componente secundário identificado, haverá outro componente secundário como ramificação do componente primário, que poderá ser objeto de um experimento comprobatório. Se o experimento evidenciar a existência do segundo componente secundário, a construção racional estará validada. Popper abre mão da episteme dos gregos, o conhecimento absoluto, demonstrável e definitivo, em prol de uma ciência transitória e conjectural. Uma afirmação deixa assim de ser verdadeira para ser válida, enquanto uma afirmação maior não a englobar ou falsear. $\mathrm{O}$ conhecimento avança ao eliminar o erro identificado na hipótese já aceita, não ao construir uma hipótese nova e definitiva (Lakatos \& Marconi, 1991).

A investigação de um fenômeno repousa em uma teoria. A teoria relaciona, ordena e explica os fatos observáveis, construindo, por lógica dedutiva, classificações, correlações, princípios e leis, com base em conceitos e axiomas. A intermediação entre os fatos e a teoria se dá pelas leis, que agrupam e resumem afinidades e permitem prever e calcular o fato e suas consequiências. A teoria não descobre as leis da natureza: estas são invenções da mente humana que explicam os fatos de uma forma causal. A teoria e o fato são conectados: a teoria só existe porque antes existiu o fato. Não há teoria que não se baseie em fatos nem há uma coleção de fatos não ordenados por uma teoria que tenha validade em uma investigação. A teoria aponta lacunas no conhecimento, desempenhando um papel no avanço da ciência. Já o fato, além de propor a teoria, reformula-a ou até mesmo a rejeita, redefinindo ou refinando as leis da natureza. Finalizando, as decorrências das teorias são apresentadas de modo determinístico, ao descrever a única manifestação de um fenômeno, e de modo probabilístico, ao descrever a expectativa de muitas dessas manifestações, reforçando, de certa forma, o argumento de Hume (Lakatos \& Marconi, 1991; Papoulis, 1984).

\subsection{Termos teóricos, construtos, conceitos e indicadores}

Ao lidar com fenômenos não manejáveis por incompatibilidade espacial, quando não há acesso, ou temporal, quando não há recorrência, o pesquisador deve lançar mão de construções abstratas que lhe facultem a investigação por meios remotos.

A construção mais abstrata é o termo teórico, que compreende os construtos e conceitos, aglutinando em si os aspectos de uma definição suficientemente ampla. As idéias contidas em expressões como "mentalidade enxuta", "satisfação de usuários" ou "pensamento estratégico" parecem ter complexidade suficiente para que se considerem termos teóricos. Os construtos também são construções abstratas, mais próximas do fenômeno que o termo teórico, mas ainda dele afastadas, consciente e deliberadamente criadas para atender a um propósito científico. Já o conceito é uma construção mais próxima da realidade que o construto. O conceito capta ou apreende fatos ou fenômenos, expressando-os por um sistema semântico, gramatical ou simbólico, de modo a torná-los inteligíveis e processáveis. O conceito não é o fenômeno, mas pode analisar e comunicar as implicações deste.

As construções abstratas podem ser definidas de modo descritivo, em que o termo é equivalente à definição (o tempo de atravessamento é o tempo que um produto leva para ser 
produzido), ou de modo estipulativo, em que um termo adquire significado de validade restrita ao ambiente em estudo (produção puxada é a produção autorizada exclusivamente por pedidos de clientes). Em ambos os casos, o pesquisador deve se precaver quanto a traduções, pois há palavras que não possuem uma tradução plena em outros idiomas (approach ou throughput do inglês, filière, do francês, saudade do português, ou paura do italiano, por exemplo). $\mathrm{O}$ pesquisador deve compreender o sentido do termo no idioma original e encontrar expressões que o recomponham no novo idioma (Lakatos \& Marconi, 1991).

Um conveniente conjunto de conceitos pode ser usado para representar hierarquicamente um construto dentro de um esquema teórico. Por exemplo, se o construto for o sucesso de um atleta em dada modalidade esportiva, com base em uma teoria, este pode ser explicado por conceitos como a força, motivação, habilidade ou inteligência. Se a inteligência for o construto, sempre com base em uma teoria, esta pode ser explicada por conceitos como a capacidade de abstração, a capacidade de leitura ou o resultado no aprendizado. O passo seguinte é especificar os aspectos constituintes do conceito que são relevantes para o objetivo da pesquisa. Esses aspectos podem ser deduzidos conforme a teoria ou observados empiricamente e são chamados de dimensões do conceito. As dimensões podem ser representadas por valores numéricos, os indicadores, que podem assumir um valor contínuo, analógico ou discreto, por valores lógicos. Em qualquer caso, é possível encontrar no indicador uma estrutura de graduação que descreve a situação da dimensão perante um referencial. Diversos indicadores podem ser combinados e resumidos quantitativamente em índices. Do mesmo modo que os construtos, os indicadores podem fazer parte de esquemas teóricos que auxiliam o pesquisador a representar a realidade na qual os fenômenos de interesse se inserem. Por exemplo, o construto "resultado no aprendizado" pode ser dividido em dimensões como precisão ao responder, rapidez de raciocínio ou prolixidade no escrever. Essas dimensões podem ser avaliadas e comparadas por indicadores, como o porcentual de respostas corretas em um teste, o número de minutos necessários para encontrar uma resposta ou o número de palavras necessárias para representar um conceito por escrito. Podem ainda ser resumidas em um único índice que pondere os três indicadores conforme uma regra de importância.

Finalizando, vai-se do fenômeno ao abstrato, partindose dos indicadores e passando pelos índices, dimensões, conceitos, construtos e termos teóricos.

\subsection{Variáveis, escalas de medição, estruturas arborescentes e circulares}

Uma variável é um conjunto de medidas associadas a um conceito, construto, aspecto, propriedade ou fator discernível em um objeto de estudo. A medida pode ser quantitativa, associada a um número, ou qualitativa, associada a uma categoria. As variáveis ligam as hipóteses e os construtos latentes, não-manifestos, ao experimento. É pela alocação de variáveis a hipóteses que os construtos e conceitos de uma teoria podem ser testados.

Variáveis admitem relacionamentos, classificações e tipologias.

As relações entre as variáveis podem ser: (i) simétricas, nas quais duas variáveis não se afetam mutuamente, ou por serem indicadores do mesmo conceito, ou por serem efeitos da mesma causa, ou por serem totalmente independentes, mas fortuitamente associadas; (ii) recíprocas, surgindo uma circularidade ou tautologia entre ambas; e (iii) assimétricas, nas quais o comportamento de uma variável afeta, condiciona, determina ou causa o comportamento da outra. Conforme a delimitação do objeto, as variáveis podem ser exógenas ou endógenas (fora ou dentro do objeto) e independentes ou dependentes (antecedem ou sucedem o fenômeno). Variáveis exógenas e/ou independentes podem ser associadas a causas ou usadas na predição de fenômenos descritos por variáveis endógenas e/ou dependentes. Variáveis dependentes e independentes podem manter entre si diversos tipos de relações de causalidade. As relações de causalidade podem ser: (i) deterministas (sempre que A ocorre, B também ocorre), que podem vir a ser tautológicas, explicitando o mesmo fenômeno com outros símbolos; (ii) suficientes (basta que haja A para haver B); (iii) necessárias (se não houver $\mathrm{A}$, não haverá $\mathrm{B}$ ); (iv) irreversíveis ou unidirecionais ( $\mathrm{A}$ afeta $\mathrm{B}, \mathrm{B}$ não afeta $\mathrm{A}$ ); e (v) reversíveis ou sistêmicas (A causa ou afeta B, B afeta ou causa A) (Lakatos \& Marconi, 1991).

As variáveis podem ser classificadas em: (i) quantitativas discretas, representáveis por números descontínuos $(1 ; 1,5$; $2 ; 2,5$; etc.); (ii) quantitativas contínuas, representáveis por quaisquer números; (iii) categóricas nominais, associadas a atributos independentes entre si (verde, vermelho, etc.); e (iv) categóricas ordinais, associadas a atributos que mantêm entre si uma estrutura de graduação (maior, menor, etc.).

A representação numérica do estado de uma variável admite quatro tipos de escalas: (i) escala nominal, que mede atributos que só admitem relações de equivalência $(=, \neq)$ (brasileiro $=0$, uruguaio $=1$, argentino $=2$, etc. $)$; (ii) ordinal, que também admite estrutura de graduação no atributo (nulo $=0$, fraco $=1$, médio $=2$, forte $=3$, dominante $=4$ ); (iii) intervalar, na qual a graduação do atributo é proporcional ao intervalo entre as escalas (a diferença entre $10^{\circ}$ e $20^{\circ} \mathrm{C}$ de temperatura é a metade da diferença entre $-10^{\circ}$ e $10^{\circ} \mathrm{C}$ ); e (iv) proporcional, na qual, além da proporção intervalar, há uma referência zero, de modo que a proporção entre atributos e escala é constante (altura, largura, peso, etc.). A escala de Likert pode ser útil para representar dados qualitativos. Essa escala utiliza cinco pontos, sendo um médio (por exemplo, ótimo, bom, regular, ruim, péssimo), e reflete os conceitos aristotélicos 
de oposição entre contrários e relatividade das categorias (Pereira, 1999).

As relações são representadas por um modelo gráfico, o diagrama de caminho (path-diagram), ou por um modelo matemático. Modelos podem usar estruturas arborescentes, representadas por regressões múltiplas, ou relações circulares, que exigem equações estruturais. Para este trabalho interessam as estruturas arborescentes.

Estruturas arborescentes utilizam a lógica da decomposição: um critério mais complexo de mensuração é dividido em subcritérios menos complexos, arranjados de modo que um subcritério só afete o critério ao qual está subordinado, não havendo subordinação múltipla. Os critérios de nível hierárquico inferior devem ser mutuamente exclusivos e devem fornecer uma descrição exaustiva do critério de nível superior. Para cada critério superior deve haver ao menos dois critérios inferiores para que se justifique a necessidade de uma estrutura arborescente (Ensslin et al., 2001; Keeney apud Ensslin et al., 2001).

A estrutura é construída a partir de uma teoria que separe e classifique o conhecimento sobre o objeto, ou por instrumentos de representação de relações, como mapas cognitivos, diagramas sistêmicos, árvores de realidade ou diagramas de influência. Esses instrumentos têm sido apresentados por diversos autores, com algumas semelhanças: (i) conexões entre causas e efeitos; (ii) explicitação dos nexos causais subjacentes às relações de causa e efeito; (iii) complexidade crescente; e (iv) representação de relações circulares. Ensslin et al. (2001) sugerem mapas cognitivos, que são grafos em que cada nó contém um construto e cada flecha contém uma relação causal ou ligação de influência. Sua construção pode ser obtida por sessões de brainstorming entre especialistas e é descrita em Ensslin et al. (2001).

Modelos de estruturas arborescentes e circulares são apresentados na Figura 1.

\subsection{Técnicas estatísticas de análise multivariada e modelagem estatística}

A investigação de modelos multivariados pode se valer de técnicas estatísticas de análise multivariada e de modelagem estatística. Diversas técnicas se aplicam, como: regressão múltipla, análise de aglomerados, análise conjunta, análise de componentes principais, análise fatorial, escalonamento multidimensional e modelagem por equações estruturadas. Para este trabalho interessam modelos em que as relações de causalidade caminham do construto para o conceito e deste para os indicadores, em ramificações arborescentes, interessando a regressão múltipla, a análise de aglomerados, a confiabilidade de medidas e as tabelas de contingência. No caso específico em estudo não será usada a regressão múltipla, mas esta técnica é mantida na revisão, pois alguma referência posterior é feita. A modelagem por equações estruturadas utiliza modelos que empregam relações circulares, mas não faz parte do escopo deste trabalho.

\subsubsection{Regressão linear múltipla}

A regressão linear múltipla é uma técnica estatística que pode ser útil na análise da relação entre uma variável dependente, a resposta, e diversas variáveis independentes, chamadas preditores, ou variáveis regressoras. $\mathrm{O}$ objetivo da técnica é usar as variáveis independentes, conhecidas, para prever a variável dependente, selecionada pelo pesquisador, cujo valor nas circunstâncias pesquisadas é desconhecido. As variáveis independentes são ponderadas por coeficientes, calculados pela técnica, que representam as contribuições individuais dos preditores para a previsão global. A relação entre os coeficientes pode indicar o grau de influência que cada preditor possui na previsão, havendo a possibilidade de dois ou mais preditores correlacionados entre si contribuírem simultaneamente para a mesma variação da resposta.

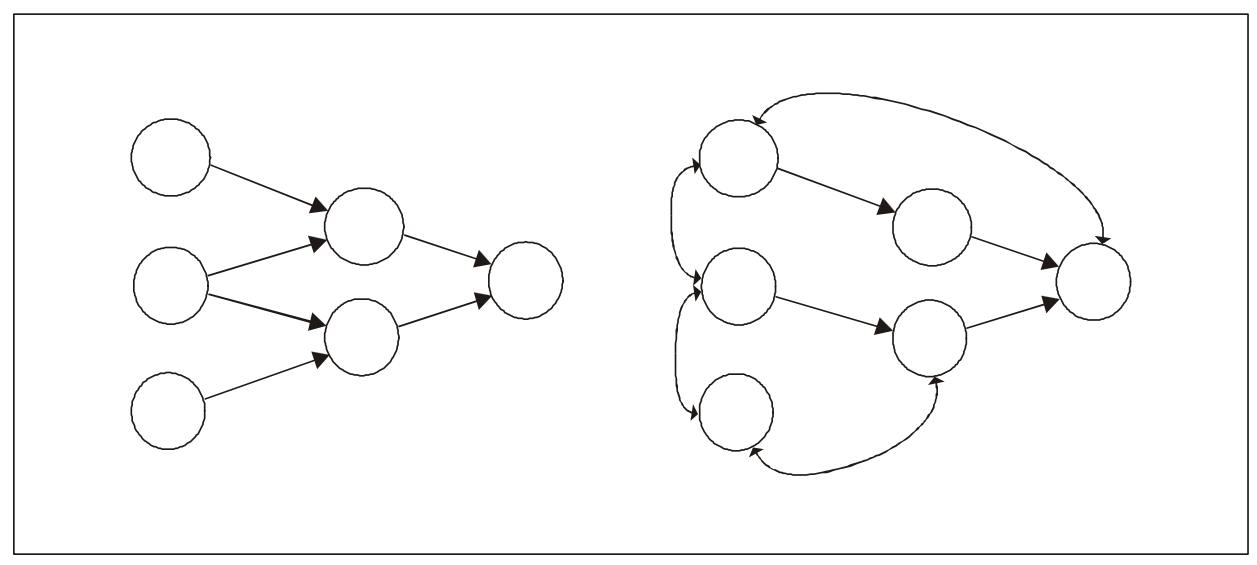

Figura 1 - Diagramas de caminho arborescente e circular. 
Apesar de ser uma técnica destinada a variáveis numéricas, sob certas circunstâncias pode ser possível incluir, como variáveis dependentes, as variáveis categóricas ou ordinais, transformadas em variáveis dicotômicas (dummyvariables), e como variáveis independentes podem ser usadas as variáveis binárias, resultando na regressão logística (Hair et al., 1998).

Na regressão linear múltipla há uma variável dependente, a resposta ou predito, e várias variáveis independentes, os preditores. A inclusão e a importância dos preditores no modelo devem ser justificadas por uma teoria que explique a relação de causalidade entre o predito e os preditores. A seleção indiscriminada ou apenas em bases empíricas de variáveis viola bases conceituais do modelo. A resposta geralmente é determinada pelo objetivo do pesquisador, mas os preditores podem incluir variáveis irrelevantes ou excluir variáveis relevantes. No primeiro caso, reduz-se a parcimônia do modelo e mascaram-se efeitos das variáveis realmente úteis, o que pode prejudicar a interpretação dos resultados. No segundo caso reduz-se a precisão do modelo e, caso a variável excluída seja correlacionada a uma variável inclusa, esta variável descreverá sozinha um efeito compartilhado. Essas considerações reforçam a necessidade de suporte teórico na escolha dos preditores (Hair et al., 1998).

A regressão linear múltipla adota a forma geral apresentada na equação 1 , na qual Y é a variável dependente ou resposta, $\beta_{0}$ é o intercepto ou termo independente, os $\beta_{n}$ são os coeficientes dos preditores e os $X_{n}$, as variáveis dependentes ou preditores.

$$
\mathrm{Y}=\beta_{0}+\beta_{1} \mathrm{X}_{1}+\beta_{2} \mathrm{X}_{2}+\ldots+\beta_{\mathrm{n}} \mathrm{X}_{\mathrm{n}}
$$

Para o cálculo dos coeficientes, parte-se de um conjunto de observações, compostas por preditores e uma resposta. Calcula-se a soma dos quadrados das diferenças entre o valor predito pelo modelo para uma dada observação e a observação real, deriva-se e iguala-se a zero. Chega-se a um sistema de equações que, resolvidas, apontam os coeficientes que produzem a menor soma quadrática de erros. Este é o método dos mínimos quadrados e será empregado na análise de regressão (Draper \& Smith, 1981).

O pesquisador pode suspeitar da existência de relações não-lineares entre a resposta e os preditores ou de interação entre preditores. Tais relações surgem em gráficos de regressão parciais, nos quais a resposta é plotada contra um único preditor. Se a disposição dos pontos não for linear, pode-se adotar a forma polinomial da equação 2 . Essa forma ainda é linear, pois a linearidade se refere aos coeficientes e não aos preditores. Vale a simbologia da equação 1 .

$$
\begin{aligned}
\mathrm{Y}= & \beta_{0}+\beta_{1} \mathrm{X}_{1}+\beta_{2} \mathrm{X}_{2}+\beta_{3} \mathrm{X}_{1}{ }_{1}+\beta_{4} \mathrm{X}_{2}{ }_{2}+\beta_{5} \mathrm{X}_{1} \mathrm{X}_{2}+\ldots \\
& +\beta_{\mathrm{n}} \mathrm{X}_{1} \mathrm{X}_{2} \mathrm{X}_{\mathrm{n}}
\end{aligned}
$$

Algumas premissas são necessárias antes de validar o modelo. Deve haver linearidade entre o fenômeno e os preditores (o coeficiente não muda ao longo do domínio do preditor) e não deve haver observações com influência desproporcional no resultado. Além disso, a variância do erro deve ser constante ao longo das observações, os erros devem ser independentes, tanto no tempo como entre si, e devem seguir uma distribuição normal.

Caso essas premissas não sejam atendidas, é possível que uma transformação nas variáveis problemáticas (radiciação, logaritmo, etc.) produza a linearidade. Verificam-se as premissas plotando um diagrama $\mathrm{X}-\mathrm{Y}$ entre preditores e resposta, que devem apresentar comportamento linear, sem pontos claramente isolados da massa de dados, ou um diagrama X-Y entre resíduos e preditos, que deve apresentar correlação próxima a zero (formato de nuvem), sem pontos claramente isolados da massa de dados. Também é possível a verificação por meio de um histograma ou papel de probabilidade normal dos erros, que deve apresentar aderência a uma distribuição normal, ou testes não-paramétricos de ajuste de normalidade, como o teste "qui-quadrado" ou o teste de Kolmogorov-Smirnoff (Hair et al., 1998).

\subsubsection{Análise de aglomerados}

Às vezes é de interesse do pesquisador separar os casos observados em grupos ou aglomerados e estudá-los pela análise de aglomerados (cluster analysis). Agrupam-se os casos de modo a maximizar a homogeneidade dentro do grupo e a heterogeneidade entre os diferentes grupos. A alocação de um dado caso a um dado aglomerado pode considerar a similaridade entre o comportamento das variáveis e também seus valores específicos. Vale observar que não há consenso referente à tradução de cluster analysis para a língua portuguesa. Diferentes autores têm usado os termos "análise de aglomerados", "análise de conglomerados" e "análise de agrupamentos". Neste artigo, optamos pelo termo "análise de aglomerados", pois este tem aparecido com maior freqüência, haja vista os artigos enviados para o Encontro Nacional de Engenharia de Produção - ENEGEP 2003.

A análise de aglomerados pode ser útil em ao menos três situações: (i) descrição taxonômica; o pesquisador classifica grande quantidade de observações em uma estrutura tipológica; (ii) simplificação de dados; cada caso passa a ser identificado pela estrutura característica do aglomerado a que pertence; e (iii) identificação de relacionamentos entre os casos, não apontados por outras técnicas e que podem emergir na composição dos aglomerados. A seleção das variáveis de caracterização dos casos deverá considerar o objetivo da análise, uma vez que esta não diferencia as variáveis relevantes das irrelevantes. A análise é prejudicada por variáveis irrelevantes ou não distintivas, de modo que o pesquisador deve eliminar do estudo aquelas que não contribuem para a segregação de casos. Finalizando, a análise de aglomerados deve ser usada apenas em base exploratória, pois não constitui uma base estatística sobre a qual se possam fazer inferências, 
não oferece uma única solução e sempre divide as observações em grupos, mesmo que não haja uma estrutura de diferenciação de dados que justifique a separação (Hair et al., 1998).

A construção dos aglomerados requer uma medição de similaridade entre os casos, que pode ser a correlação ou a distância euclidiana entre as variáveis. Os aglomerados resultantes podem ser diferentes para cada caso: se a medida de similaridade for a correlação, os aglomerados poderão conter casos com valores muito diferentes, mas com perfis semelhantes. Se a medida de similaridade for a distância euclidiana, os aglomerados conterão valores muito próximos, mesmo que com perfis diferentes (Hair et al., 1998).

Os métodos de construção dos aglomerados podem assumir dois tipos.

Nos métodos hierárquicos, a próxima solução está embutida na solução anterior, dela derivando e para ela podendo voltar. No modo aglomerativo, cada caso inicia como um aglomerado. A seguir, cada dois aglomerados mais próximos são combinados até que se atinja o número de aglomerados especificado. Por ser hierárquica, uma solução está embutida na anterior, podendo a ela retornar, bastando que se desfaça a última operação. $\mathrm{O}$ modo divisivo começa tomando o total das observações como um único aglomerado. A seguir, os casos mais dissimilares são separados até que se chegue ao número de aglomerados desejado. Como os softwares estatísticos mais usados empregam os métodos aglomerativos e os métodos divisivos operam como métodos aglomerativos ao contrário, o uso dos métodos aglomerativos prevalece. O procedimento single-linkage é baseado na menor distância entre casos. Os dois casos menos distantes são unidos, formando o primeiro aglomerado. O próximo caso se une ao primeiro aglomerado ou os próximos dois casos formam um segundo aglomerado. O processo se repete até que todos os casos tenham sido inclusos ou se tenha atingido o número de aglomerados desejado. O procedimento complete-linkage é similar ao anterior, menos em relação ao critério de inclusão, que é a mínima distância máxima entre os aglomerados. Este método evita um inconveniente do método anterior: a formação de estruturas em forma de filas. O próximo procedimento é o average-linkage, similar aos anteriores, diferindo no critério de inclusão, que é a mínima distância média entre os aglomerados. Este método tende a formar aglomerados com pequena variação interna, pois é imune a valores extremos. Tem-se ainda o método dos centróides, no qual a distância entre aglomerados é a distância entre os centróides, ou seja, o ponto médio entre as observações. Este método apresenta a característica de que, para cada operação, o centróide muda de lugar, podendo gerar alguma iteratividade. O último método aglomerativo é o de Ward. Neste método, o critério de formação de aglomerados é minimizar a soma dos quadrados das distâncias entre os casos contidos em cada aglomerado. Este método tende a formar aglomerados de pequeno tamanho e de mesmo número de casos (Hair et al., 1998).

Os métodos não-hierárquicos são chamados de $K$-means e não usam construções ramificadas, alocando os casos aos aglomerados de acordo com o número de aglomerados desejados. Portanto, uma solução envolvendo, por exemplo, seis aglomerados não provém de uma solução anterior de cinco ou de sete aglomerados, mas é a melhor solução de seis aglomerados apontada conforme um método. Tipicamente, escolhe-se uma semente de aglomerado e um limite ao redor da semente, alocando-se os casos dentro do limite da semente. Há diversas abordagens para localizar a semente e o limite: no método do limite sequiencial se especifica a semente e o limite e se incluem todos os casos pertinentes. A seguir se escolhem outra semente e outro limite até que todos os casos tenham sido incluídos. No método dos limites paralelos, escolhem-se diversas sementes e limites ao mesmo tempo e os casos pertinentes são alocados à semente. O limite varia até ser concluída a alocação. O último método é o da otimização, similar aos anteriores, porém permite que um caso já alocado migre para outro aglomerado. O principal problema com os métodos não-hierárquicos é a seleção das sementes. Os softwares estatísticos resolvem esse problema de diversos modos, mas mesmo sementes randômicas podem gerar soluções diferentes. O pesquisador deve estar atento ao impacto da escolha da semente na solução final (Hair et al., 1998).

No Quadro 1 se apresentam os tipos de métodos para análise de aglomerados.

Quadro 1 - Classificação dos métodos de análise de aglomerados. Fonte: Hair et al. (1998).

\begin{tabular}{ccc}
\hline & & Single-linkage \\
& & Complete-linkage \\
Métodos hierárquicos & Aglomerativos & Average-linkage \\
& & Centróides \\
& & Método de Ward \\
\cline { 2 - 3 } Métodos não-hierárquicos & Divisivos & \\
\cline { 2 - 3 }$(k$-means $)$ & Limites sequienciais & \\
& Limites paralelos \\
& Otimização & \\
\hline
\end{tabular}




\subsection{Confiabilidade e erros nas medições}

Um modelo de representação do conhecimento acerca de um fenômeno pode se valer de variáveis manifestas, que se medem diretamente, ou variáveis latentes, não mensuráveis, mas calculáveis a partir das variáveis manifestas. A representatividade do modelo pode ser melhorada melhorando-se a representatividade dos conceitos latentes e reduzindo-se os erros de medição. Ao relacionar as variáveis de um modelo, deve-se considerar dois tipos de erros: erros conceituais, causados por entendimentos diferentes acerca dos conceitos latentes, e erros decorrentes da confiabilidade nas medidas da variável preditora. A correlação observada entre uma variável preditora e uma variável predita será sempre menor do que a correlação real, a não ser que haja confiabilidade total nas medições. Portanto, ao aumentar a confiabilidade da medição, aumenta-se a precisão do modelo.

Os erros conceituais se originam da necessidade de se inserirem conceitos latentes no modelo. Um modo de investigar esse tipo de conceito é a proposição de perguntas a respondentes. As perguntas podem não representar com exatidão o conceito a investigar ou os respondentes podem não relacionar as perguntas com o tema investigado. Uma técnica capaz de medir a magnitude do erro cometido pelos respondentes permitirá incorporar a confiabilidade na estimativa e contribuir para melhorar o modelo.

Se um conjunto de indicadores tiver a característica da unidimensionalidade, ou seja, cada indicador participa da representação de um único conceito ou construto, é possível testar sua confiabilidade. Por confiabilidade de indicadores entende-se a consistência com a qual esses indicadores representam o conceito ou construto latente ao qual estão designados. Indicadores de construtos de alta confiabilidade são altamente intercorrelacionados, indicando que todos eles medem o mesmo construto. Caso os indicadores sejam entendidos pelos respondentes como representativos de construtos diferentes, surge um erro de mensuração e a confiabilidade da medição cai. Uma maneira de medir a confiabilidade dos indicadores que compõem um construto é o teste do alfa de Crombach. Esse teste oferece como saída um valor compreendido entre 0 e 1 , sendo 1 a situação de máxima confiabilidade. $\mathrm{O}$ teste oferece ainda o novo valor de saída que seria obtido caso cada indicador fosse eliminado do modelo. Com isso, é possível identificar o(s) indicador(es) que contribui(em) para a redução da confiabilidade da medição e elimina-lo(s) ou modifica-lo(s). Reciprocamente, para que a amostra não seja contaminada por um indivíduo cuja compreensão do construto seja muito diferentes dos demais, pode-se investigar os respondentes que mais contribuem para a perda da confiabilidade (Hair et al., 1998).

O alfa de Crombach se baseia em correlações entre variáveis calculadas pela razão entre covariâncias e variâncias. Quanto mais as variações conjuntas entre as diferentes medidas do fenômeno superarem as variações individuais, melhor será a confiabilidade do construto. Do mesmo modo, quanto mais indicadores forem mensurados, maior será essa confiabilidade. A fórmula para o cálculo do alfa de Crombach é apresentada na equação 3 , em que $k$ é o número de indicadores que compõem o construto latente e cov e var são, respectivamente, as covariâncias e as variâncias dos indicadores (Pereira, 1999).

$$
\alpha=\frac{k \cdot\left(\frac{\overline{\overline{\mathrm{cov}}}}{\overline{\mathrm{var}}}\right)}{1+(k-1) \cdot\left(\frac{\overline{\mathrm{cov}}}{\overline{\mathrm{var}}}\right)}
$$

\subsection{Sistemas de medição de resultados organizacionais}

Uma parte relevante do planejamento estratégico das organizações é a medição de seus resultados. Se a medição for incompatível com os objetivos estratégicos, estes podem não ser atingidos. Para Bititci (1995), um sistema de medição de resultados deve ter algumas capacidades: (i) formar visão holística, evitando a subotimização local; (ii) desdobrar os objetivos estratégicos até os níveis operacionais; (iii) proporcionar o pleno entendimento da estrutura dos objetivos e dos conflitos; (iv) adotar uma forma hierárquica, similar a um sistema de informações, considerando a capacidade operacional da organização em coletar e armazenar os dados requeridos; e (v) considerar aspectos da cultura organizacional.

Diversas alternativas de medições têm sido discutidas no meio acadêmico e aplicadas no meio empresarial. Dentre estas, para o objetivo deste trabalho, interessam o modelo Quantum, o Balanced Scorecard (BSC) e os modelos baseados no prêmio Malcolm Baldridge.

O modelo Quantum, proposto por Hronec (1993), mede o desempenho por uma matriz na qual são avaliadas a qualidade, o tempo de execução e o custo por meio da organização, processos e pessoas. O serviço é avaliado quanto à sua qualidade intrínseca, quanto ao tempo que requer para sua execução e quanto ao custo que acarreta. Em termos de organização, os três construtos são avaliados de acordo com as influências que causam nas relações da empresa com o mercado em que atua. Em termos de processo, a avaliação se dá de acordo com as influências e repercussões nos processos da empresa. Finalmente, em termos de pessoas, avalia-se a atuação dos construtos nos postos pessoais de trabalho. As nove avaliações, cruzadas, caracterizam o desempenho, sendo conveniente o uso de medições categóricas.

O BSC tem atraído a atenção de teóricos e de praticantes. Speckbacher et al. (2003) apresentam um panorama que aponta sua importância atual. O objetivo inicial do BSC era propor uma alternativa às tradicionais medições financeiras, 
míopes e de curto prazo, que também incorporasse o valor dos ativos intangíveis, cada vez mais decisivos na nova economia (Sohn et al., 2003). De início, o BSC apenas associou três novas perspectivas às medições financeiras então existentes: clientes, processos e aprendizagem, sugerindo que o desempenho estratégico seria baseado em quatro resultados, não mais apenas no resultado financeiro. À medida que o entendimento sobre o BSC avançou, a própria execução da estratégia passou a ser mensurada, assumindo a forma de redes de relações causais, que geralmente se iniciam no aprendizado, passam por processos e clientes e chegam ao resultado financeiro. Speckbacher et al. (2003) identificam e descrevem a evolução do entendimento dos especialistas e comparam e tipificam aplicações do BSC.

O prêmio Malcolm Baldridge (Malcolm Baldrige National Quality Award) foi criado em 1987 com o objetivo de promover a busca da excelência em organizações públicas e privadas, de negócios, saúde e educação, principalmente em decorrência da perda de competitividade pela qual passava a economia americana. Entre os objetivos específicos do prêmio há um método padronizado de medição de desempenho, estruturado em sete construtos e dezenove variáveis categóricas, e que pode servir de guia para os esforços de gestão. Os construtos são: liderança, planejamento estratégico, foco no cliente e no mercado, medição, análise e gestão do conhecimento, recursos humanos, processos e resultados. $\mathrm{O}$ cálculo final é linear, considerando os pesos dos construtos e das variáveis, porém os organizadores do prêmio propõem um modelo circular para as relações entre os construtos (BNQP, 2003, p. 5). No Brasil, diversas organizações propõem e administram prêmios similares, com algumas modificações nas variáveis e nos pesos, como a fundação para o Prêmio Nacional da Qualidade (PNQ) e a Associação Nacional de Transportadores de Passageiros (ANTP).

\section{Metodologia proposta}

Concluída a revisão teórica, apresenta-se a metodologia proposta para a construção de um indicador capaz de medir um conceito intangível relevante em um sistema produtivo. O procedimento está organizado em seis passos:

- Passo 1: especificar o termo teórico ou construto que melhor define o conceito intangível de interesse, a partir de agora chamado de termo de topo.

- Passo 2: com base em uma teoria, desdobrar o termo de topo em tantos construtos quantos necessários para descrevê-lo. Não havendo uma teoria, uma pesquisa empírica deve ser realizada com especialistas, formandose a primeira camada.

- Passo 3: com base em teorias ou pesquisas empíricas, desdobra-se a primeira camada em tantas camadas quantas necessárias até que o termo de topo seja suficientemente descrito. A última camada deve necessariamente ser composta por indicadores, ou seja, variáveis manifestas que serão medidas por experimentos ou por pesquisas de informação.

- Passo 4: resumir as relações obtidas em um diagrama de caminho. Questionar as relações em busca de efeitos sistêmicos. Se o diagrama de caminho puder ser simplificado para uma estrutura arborescente e ainda assim o fenômeno for suficientemente descrito, deve-se abrir mão das relações circulares e manter a unidimensionalidade.

- Passo 5: definir o instrumento de pesquisa das variáveis manifestas, contendo uma escala numérica, e aplicar ao objeto de interesse. Se a unidimensionalidade for preservada, aplicar um teste, tal como o teste do alfa de Crombach, para medir a confiabilidade da pesquisa. Se necessário, alterar perguntas ou eliminar respondentes para refinar as respostas.

- Passo 6: em uma estrutura arborescente de duas camadas, as variáveis manifestas são os preditores dos construtos que, por sua vez, são os preditores do termo de topo. Calculam-se os coeficientes por um dos seguintes métodos: (i) uso de uma teoria já existente; (ii) conhecimentos empíricos do pesquisador; (iii) determinação de coeficientes por ponderação da opinião de especialistas; (iv) repetição de experimentos e uso da regressão múltipla; ou (v) não havendo justificativa para o contrário, adotar coeficientes unitários. Definidos os coeficientes e respondidos os questionários, medem-se os construtos e o termo de topo.

O escopo deste trabalho não inclui fenômenos que exijam relações circulares.

\section{Exemplo de aplicação da metodologia proposta}

A metodologia proposta foi aplicada a uma indústria de serviços, mais especificamente às quinze empresas de transporte coletivo de Porto Alegre. Essa indústria enfrenta, em quase todas as capitais estaduais, redução contínua do número de usuários, decorrente de causas estruturais desestimulantes do transporte coletivo. Para fazer frente a esse cenário de negócios, diversas alternativas têm sido tentadas pelo setor, como os modelos gerenciais baseados no prêmio Malcolm Baldridge e a certificação ISO 9000. Uma alternativa que ainda não foi proposta ao setor é a introdução da mentalidade enxuta, apresentada nas obras dos pesquisadores do MIT James Womack e Daniel Jones e pelo Lean Enterprise Institute. A mentalidade enxuta deve, no entanto, ser adaptada à realidade das empresas de transporte coletivo para que possa gerar um modelo de gestão aplicável, o que motivou este estudo. 
O desenvolvimento do estudo, em cada uma de suas etapas, aparece descrito a seguir.

- Passos 1 e 2: identificação do termo teórico e seus construtos.

O objetivo da pesquisa é investigar a compreensão do termo teórico "mentalidade enxuta" na indústria de transporte coletivo. Como há uma teoria, não são necessários os experimentos nem a regressão múltipla. A teoria trata cada construto separadamente, com abordagens específicas, sugerindo o formato arborescente com cinco construtos (Womack \& Jones, 1997): (i) capacidade de compreender o que agrega valor ao cliente ou usuário do serviço; (ii) capacidade de eliminar perdas na cadeia de produção de valor da indústria; (iii) capacidade de tornar a operação previsível; (iv) capacidade de permitir que o cliente "puxe" a operação; e (v) capacidade de medir e melhorar o resultado continuamente.
- Passos 3 e 4: identificação das variáveis manifestas e dos indicadores e resumo das relações obtidas em um diagrama de caminho.

Pela análise teórica de especialistas em transporte e em mentalidade enxuta, em sessões de brainstorming, e com o apoio de mapas cognitivos, cada construto foi associado a seis variáveis manifestas do tipo categóricas nominais, em princípio mutuamente exclusivas. Essas variáveis foram medidas por questionários, com cinco opções de respostas, de "totalmente negativo" a "totalmente positivo", passando pelas graduações intermediárias e por um ponto neutro. Ao relacionar e tratar cada construto separadamente e por abordagens específicas, a teoria, em princípio, não exige o formato circular. O Quadro 2 relaciona os construtos e as variáveis manifestas de apoio, evidenciando a estrutura arborescente. Descreve-se, portanto, a mentalidade enxuta por seus construtos, obtidos a partir das respectivas variáveis manifestas.

\section{Quadro 2 - Estrutura do objeto em investigação.}

\begin{tabular}{|c|c|c|}
\hline Termo teórico & Construto & Variável manifesta \\
\hline \multirow{30}{*}{$\begin{array}{l}\text { Mentalidade } \\
\text { enxuta }\end{array}$} & \multirow{6}{*}{$\begin{array}{c}\text { Capacidade de compreender o } \\
\text { que agrega valor ao cliente ou } \\
\text { usuário do serviço }\end{array}$} & Conhecimento das características dos clientes \\
\hline & & Conhecimento das finalidades dos clientes \\
\hline & & Conhecimento dos fatores de decisão dos clientes \\
\hline & & Conhecimento dos momentos em que o usuário toma o serviço \\
\hline & & Conhecimento dos ritmos de tomada de serviços \\
\hline & & Conhecimento dos locais de tomada de serviços \\
\hline & \multirow{6}{*}{$\begin{array}{c}\text { Capacidade de eliminar perdas na } \\
\text { cadeia de produção de valor da } \\
\text { indústria }\end{array}$} & Conhecimento do conceito de perda \\
\hline & & Capacidade de identificar suas perdas \\
\hline & & Capacidade de tipificar suas perdas \\
\hline & & Capacidade de medir suas perdas \\
\hline & & Capacidade de eliminar suas perdas \\
\hline & & Importância da redução de tempos na prestação do serviço \\
\hline & \multirow{6}{*}{$\begin{array}{c}\text { Capacidade de tornar a operação } \\
\text { previsível }\end{array}$} & Conhecimento de seus processos \\
\hline & & Importância dada ao mapeamento de seus processos \\
\hline & & Importância dada à medição de processos internos \\
\hline & & Importância dada à medição de processos de parceiros \\
\hline & & Vontade de mudar processos \\
\hline & & Capacidade de entender a multifuncionalidade \\
\hline & \multirow{6}{*}{$\begin{array}{l}\text { Capacidade de permitir que o cliente } \\
\text { "puxe" a operação }\end{array}$} & Capacidade instrumental de ouvir a voz do cliente \\
\hline & & Qualidade da análise dedicada à voz do cliente \\
\hline & & Importância dada à voz do cliente \\
\hline & & Capacidade instrumental de aproveitar a voz do cliente \\
\hline & & Vontade da empresa de aproveitar a voz do cliente \\
\hline & & Intensidade do estímulo à interação com o cliente \\
\hline & \multirow{6}{*}{$\begin{array}{l}\text { Capacidade de medir e melhorar o } \\
\text { resultado continuamente }\end{array}$} & Conhecimento do conceito de melhoria contínua \\
\hline & & Capacidade de promover a melhoria contínua \\
\hline & & Capacidade de priorizar ações de melhoria contínua \\
\hline & & Capacidade de controlar a melhoria contínua \\
\hline & & Importância dada à melhoria contínua \\
\hline & & Intensidade da melhoria contínua \\
\hline
\end{tabular}


- Passo 5: definir o instrumento de pesquisa, aplicar e testar.

As variáveis manifestas foram investigadas por meio de questionários respondidos pelas quinze empresas. A cada variável foram atribuídas alternativas de respostas, associadas a valores oscilando entre 1 (totalmente negativo) e 5 (totalmente positivo).

- Passo 6: modelo matemático: determinação dos coeficientes.

Foram usadas duas abordagens para a determinação dos coeficientes: (i) uso ad-hoc de coeficientes unitários, de acordo com o modelo de cálculo da equação 4, na qual os $\mathrm{P}_{\mathrm{i}}$ são os valores das respostas aos questionários; e (ii) opinião ponderada de especialistas em mentalidade enxuta, segundo o modelo de cálculo da equação 5, na qual os coeficientes $\mathrm{C}_{2 \mathrm{i}}$ são os 30 coeficientes da segunda camada, os coeficientes $\mathrm{C}_{1 \mathrm{j}}$ são os 5 coeficientes da primeira camada, os valores $\mathrm{P}_{\mathrm{i}}$ são os valores das respostas aos questionários e os valores independentes consideram os valores extremos do modelo, 30 e 150.

$$
\begin{gathered}
\text { ME \% unit. }=\left(\Sigma \mathrm{P}_{\mathrm{i}}-30\right) / 1,2 \\
\text { ME \% pond. }=\left(\Sigma \mathrm{C}_{2 \mathrm{i}} \cdot \mathrm{C}_{1 \mathrm{j}} \cdot \mathrm{P}_{\mathrm{i}}-30\right) / 1,2
\end{gathered}
$$

O cálculo dos coeficientes ponderados por opiniões de especialistas foi antecedido por uma seleção prévia, que garantiu certa homogeneidade de opiniões. Seis especialistas com opiniões semelhantes ordenaram por importância os cinco construtos da primeira camada. Uma das respostas foi descartada por divergir demais das outras cinco. Os especialistas remanescentes então ordenaram por importância as seis variáveis manifestas que apóiam cada construto. A regra de avaliação da opinião dos especialistas e os resultados obtidos para os coeficientes são apresentados no Quadro 3 e nas Tabelas 1 e 2.

$\mathrm{Na}$ Tabela 3 são apresentados os valores atribuídos às respostas de cada respondente, os resultados da aplicação do modelo unitário e do modelo ponderado e os alfa de Crombach de cada construto, calculados pelas respostas dos 15 respondentes às 6 respectivas variáveis. A bibliografia aceita $70 \%$ e 50\% para pesquisas exploratórias (Hair et al., 1998).

O construto menos confiável é o quarto, seguido pelo terceiro, se bem que os valores, 0,67 e 0,64, não diferemmuito dos valores aceitos. Na Tabela 4 têm-se as análises oferecidas pelo software SPSS, surgindo as variáveis manifestas "importância dada à voz do cliente" e "capacidade de entender a multifuncionalidade" como maiores suscitadoras de dúvidas. Como a diferença entre os resultados dos modelos é pequena e não houve inversão de ordem, conclui-se que, para o caso em estudo, o uso de coeficientes unitários é satisfatório, não se justificando a adoção dos coeficientes ponderados com a regra de ponderação adotada.

Quadro 3 - Regras de avaliação da opinião dos especialistas.

\begin{tabular}{cc}
\hline Primeira camada & Segunda camada \\
\hline $1^{\mathrm{o}}$ lugar $=1,2$ & $1^{\mathrm{o}}$ lugar $=1,25$ \\
$2^{\mathrm{o}}$ lugar $=1,1$ & $2^{\mathrm{o}}$ lugar $=1,15$ \\
$3^{\mathrm{o}}$ lugar $=1,0$ & $3^{\mathrm{o}}$ lugar $=1,05$ \\
$4^{\mathrm{o}}$ lugar $=0,9$ & $4^{\mathrm{o}}$ lugar $=0,95$ \\
$5^{\mathrm{o}}$ lugar $=0,8$ & $5^{\mathrm{o}}$ lugar $=0,85$ \\
& $6^{\mathrm{o}}$ lugar $=0,75$ \\
\hline
\end{tabular}

\begin{tabular}{|c|c|c|c|c|c|}
\hline & \multicolumn{5}{|c|}{$1^{\circ}$ construto $2^{\circ}$ construto $3^{\circ}$ construto $4^{\circ}$ construto $5^{\circ}$ construto } \\
\hline $1^{\circ}$ especialista & $1^{\underline{o}}$ & $5^{\circ}$ & $4^{\mathrm{o}}$ & $2^{\underline{o}}$ & $3^{\underline{0}}$ \\
\hline $2^{\underline{0}}$ especialista & $1^{\underline{o}}$ & $2^{\mathrm{o}}$ & $3^{\mathrm{o}}$ & $4^{\mathrm{o}}$ & $5^{\mathrm{o}}$ \\
\hline $3^{\circ}$ especialista & $1^{\underline{o}}$ & $2^{\underline{0}}$ & $4^{\mathrm{o}}$ & $5^{\mathrm{o}}$ & $3^{0}$ \\
\hline $4^{\circ}$ especialista & $1^{\underline{o}}$ & $5^{\mathrm{o}}$ & $3^{\mathrm{o}}$ & $4^{\mathrm{o}}$ & $2^{\underline{o}}$ \\
\hline $5^{\circ}$ especialista & $2^{\underline{o}}$ & $1^{\mathrm{o}}$ & $5^{\mathrm{o}}$ & $3^{\mathrm{o}}$ & $4^{\mathrm{o}}$ \\
\hline Soma & 5,9 & 5 & 4,6 & 4,7 & 4,8 \\
\hline média = coef. & 1,18 & 1 & 0,92 & 0,94 & 0,96 \\
\hline ordem & 1 & 2 & 5 & 4 & 3 \\
\hline \multicolumn{3}{|c|}{ média dos coeficientes $=1$; } & \multicolumn{3}{|c|}{ desvio-padrão dos coeficientes $=0,10$} \\
\hline
\end{tabular}

Tabela 1 - Coeficientes da primeira camada da mentalidade enxuta. 
Tabela 2 - Coeficientes da segunda camada da mentalidade enxuta.

\begin{tabular}{ccccccccc}
\hline & $\mathbf{1}^{\mathbf{0}}$ coef. & $\mathbf{2}^{\mathbf{o}}$ coef. & $\mathbf{3}^{\mathbf{0}}$ coef. & $\mathbf{4}^{\mathbf{0}}$ coef. & $\mathbf{5}^{\mathbf{0}}$ coef. & $\mathbf{6}^{\mathbf{0}}$ coef. & média & desv.-pad. \\
\hline $1^{\mathrm{o}}$ construto & 1,07 & 1,23 & 1,05 & 0,97 & 0,85 & 0,83 & 1 & 0,14 \\
$2^{\mathrm{o}}$ construto & 1,13 & 1,15 & 0,87 & 0,93 & 1,05 & 0,87 & 1 & 0,12 \\
$3^{\mathrm{o}}$ construto & 1,19 & 1,03 & 1,05 & 0,89 & 0,97 & 0,87 & 1 & 0,11 \\
$4^{\mathrm{o}}$ construto & 0,99 & 0,93 & 1,15 & 0,97 & 1,01 & 0,95 & 1 & 0,08 \\
$5^{\circ}$ construto & 1,09 & 0,99 & 1,09 & 0,91 & 1,09 & 0,83 & 1 & 0,08 \\
média $=$ & 1,09 & 1,07 & 1,04 & 0,93 & 0,99 & 0,87 & 1 & \\
desvio-padrão $=$ & 0,07 & 0,12 & 0,10 & 0,04 & 0,09 & 0,05 & & \\
\hline
\end{tabular}

Tabela 3 - Tabulação das respostas (de Crombach calculado pelo software SPSS for Windows, v. 8.0.0).

\begin{tabular}{|c|c|c|c|c|c|c|c|c|c|c|c|c|c|c|c|c|c|}
\hline & 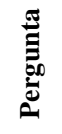 & $\begin{array}{l}\overrightarrow{\dot{a}} \\
\stackrel{0}{3} \\
\stackrel{4}{4}\end{array}$ & $\stackrel{\sim}{\dot{q}}$ & $\begin{array}{l}\ddot{2} \\
\ddot{0} \\
\approx\end{array}$ & $\begin{array}{l}\dot{0} \\
\dot{0} \\
\approx\end{array}$ & $\begin{array}{l}n \\
\dot{0} \\
\approx\end{array}$ & $\begin{array}{l}0 \\
\dot{0} \\
\ddot{0}\end{array}$ & $\stackrel{\dot{0}}{\tilde{0}}$ & $\stackrel{\infty}{\dot{0}}$ & 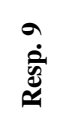 & 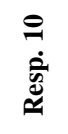 & $\begin{array}{l}= \\
\dot{\overline{3}} \\
\simeq\end{array}$ & $\begin{array}{l}\text { ป } \\
\dot{\dot{n}} \\
\simeq 4\end{array}$ & $\begin{array}{l}\ddot{7} \\
\dot{0} \\
\stackrel{3}{4}\end{array}$ & 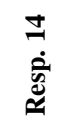 & $\begin{array}{l}\stackrel{2}{2} \\
\dot{0} \\
\simeq\end{array}$ & 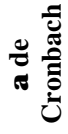 \\
\hline \multirow{6}{*}{ 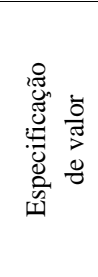 } & 1 & 5 & 4 & 4 & 4 & 2 & 4 & 5 & 3 & 3 & 4 & 2 & 4 & 3 & 2 & 2 & \multirow{6}{*}{0,86} \\
\hline & 2 & 4 & 4 & 4 & 5 & 3 & 4 & 4 & 4 & 3 & 5 & 3 & 5 & 3 & 2 & 3 & \\
\hline & 3 & 4 & 4 & 3 & 4 & 4 & 4 & 4 & 4 & 3 & 5 & 4 & 4 & 3 & 2 & 3 & \\
\hline & 4 & 5 & 5 & 4 & 5 & 4 & 4 & 4 & 5 & 1 & 5 & 5 & 4 & 4 & 4 & 3 & \\
\hline & 5 & 5 & 4 & 4 & 4 & 5 & 5 & 4 & 5 & 1 & 5 & 5 & 4 & 4 & 3 & 2 & \\
\hline & 6 & 4 & 4 & 4 & 4 & 5 & 5 & 4 & 4 & 3 & 5 & 3 & 4 & 4 & 3 & 3 & \\
\hline \multirow{6}{*}{ 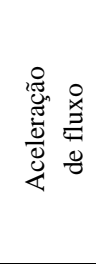 } & 7 & 4 & 3 & 4 & 3 & 3 & 4 & 3 & 1 & 4 & 4 & 2 & 4 & 3 & 1 & 2 & \multirow{6}{*}{0,92} \\
\hline & 8 & 4 & 4 & 5 & 2 & 2 & 4 & 4 & 1 & 3 & 4 & 3 & 4 & 3 & 1 & 2 & \\
\hline & 9 & 4 & 4 & 4 & 3 & 3 & 4 & 3 & 1 & 3 & 4 & 3 & 3 & 2 & 1 & 2 & \\
\hline & 10 & 3 & 4 & 4 & 3 & 3 & 4 & 4 & 1 & 3 & 4 & 3 & 3 & 2 & 1 & 3 & \\
\hline & 11 & 5 & 5 & 4 & 5 & 4 & 5 & 4 & 1 & 4 & 4 & 1 & 4 & 1 & 1 & 1 & \\
\hline & 12 & 3 & 3 & 3 & 3 & 3 & 2 & 3 & 3 & 3 & 3 & 3 & 3 & 1 & 1 & 2 & \\
\hline \multirow{6}{*}{ 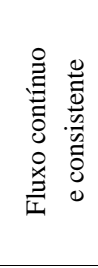 } & 13 & 5 & 5 & 5 & 5 & 5 & 5 & 5 & 4 & 5 & 5 & 3 & 4 & 4 & 5 & 4 & \multirow{6}{*}{0,67} \\
\hline & 14 & 5 & 4 & 5 & 4 & 5 & 5 & 4 & 1 & 4 & 5 & 1 & 1 & 1 & 5 & 5 & \\
\hline & 15 & 5 & 5 & 5 & 5 & 5 & 5 & 5 & 1 & 4 & 5 & 1 & 4 & 4 & 5 & 5 & \\
\hline & 16 & 5 & 5 & 5 & 5 & 4 & 5 & 1 & 4 & 1 & 5 & 1 & 4 & 4 & 4 & 5 & \\
\hline & 17 & 5 & 5 & 4 & 4 & 4 & 5 & 4 & 4 & 1 & 5 & 4 & 4 & 4 & 5 & 5 & \\
\hline & 18 & 2 & 3 & 2 & 2 & 2 & 1 & 3 & 3 & 3 & 3 & 3 & 3 & 2 & 2 & 2 & \\
\hline \multirow{6}{*}{ 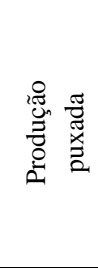 } & 19 & 5 & 5 & 4 & 4 & 3 & 5 & 5 & 1 & 4 & 5 & 1 & 5 & 5 & 1 & 5 & \multirow{6}{*}{0,64} \\
\hline & 20 & 5 & 5 & 4 & 4 & 4 & 5 & 5 & 5 & 4 & 5 & 2 & 5 & 5 & 4 & 5 & \\
\hline & 21 & 5 & 4 & 4 & 4 & 5 & 5 & 5 & 4 & 4 & 5 & 5 & 4 & 4 & 4 & 5 & \\
\hline & 22 & 5 & 4 & 4 & 4 & 5 & 5 & 4 & 4 & 4 & 5 & 4 & 4 & 5 & 4 & 4 & \\
\hline & 23 & 5 & 5 & 5 & 5 & 4 & 5 & 4 & 5 & 4 & 5 & 4 & 4 & 5 & 4 & 5 & \\
\hline & 24 & 4 & 4 & 4 & 4 & 2 & 5 & 4 & 3 & 3 & 4 & 4 & 3 & 4 & 3 & 2 & \\
\hline \multirow{6}{*}{ 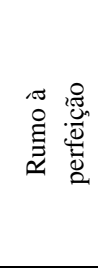 } & 25 & 5 & 4 & 5 & 4 & 4 & 4 & 5 & 1 & 4 & 4 & 3 & 4 & 3 & 2 & 4 & \multirow{6}{*}{0,93} \\
\hline & 26 & 5 & 5 & 5 & 5 & 5 & 5 & 4 & 1 & 4 & 5 & 1 & 4 & 1 & 1 & 5 & \\
\hline & 27 & 5 & 5 & 5 & 5 & 1 & 5 & 4 & 1 & 4 & 5 & 1 & 4 & 1 & 1 & 5 & \\
\hline & 28 & 5 & 5 & 4 & 5 & 4 & 5 & 4 & 1 & 4 & 5 & 1 & 4 & 4 & 1 & 5 & \\
\hline & 29 & 5 & 5 & 4 & 1 & 1 & 5 & 4 & 1 & 4 & 4 & 1 & 4 & 4 & 1 & 3 & \\
\hline & 30 & 4 & 4 & 3 & 3 & 3 & 4 & 3 & 1 & 3 & 4 & 2 & 3 & 3 & 1 & 4 & \\
\hline \multicolumn{3}{|c|}{ ME $\%$ unit. $=87,5$} & 83,3 & 78,3 & 73,3 & 64,2 & 85,8 & 74,2 & 40 & 56,7 & 88,3 & 40,8 & 70 & 55 & 37,5 & 63,3 & \\
\hline \multicolumn{2}{|c|}{ ordem } & 2 & 4 & 5 & 7 & 9 & 3 & 6 & 14 & 11 & 1 & 13 & 8 & 12 & 15 & 10 & \\
\hline \multirow{2}{*}{\multicolumn{2}{|c|}{$\begin{array}{c}\text { ME } \% \text { pond. = } \\
\text { ordem }\end{array}$}} & 87,9 & 83,2 & 78,7 & 73,9 & 63,7 & 86 & 75,3 & 40,8 & 56,9 & 88,7 & 41,7 & 71 & 54,8 & 37,1 & 62 & \\
\hline & & 2 & 4 & 5 & 7 & 9 & 3 & 6 & 14 & 11 & 1 & 13 & 8 & 12 & 15 & 10 & \\
\hline
\end{tabular}


Tabela 4 - Teste de confiabilidade para os construtos 3 e 4. Fonte: software SPSS for Windows, v. 8.0.0.

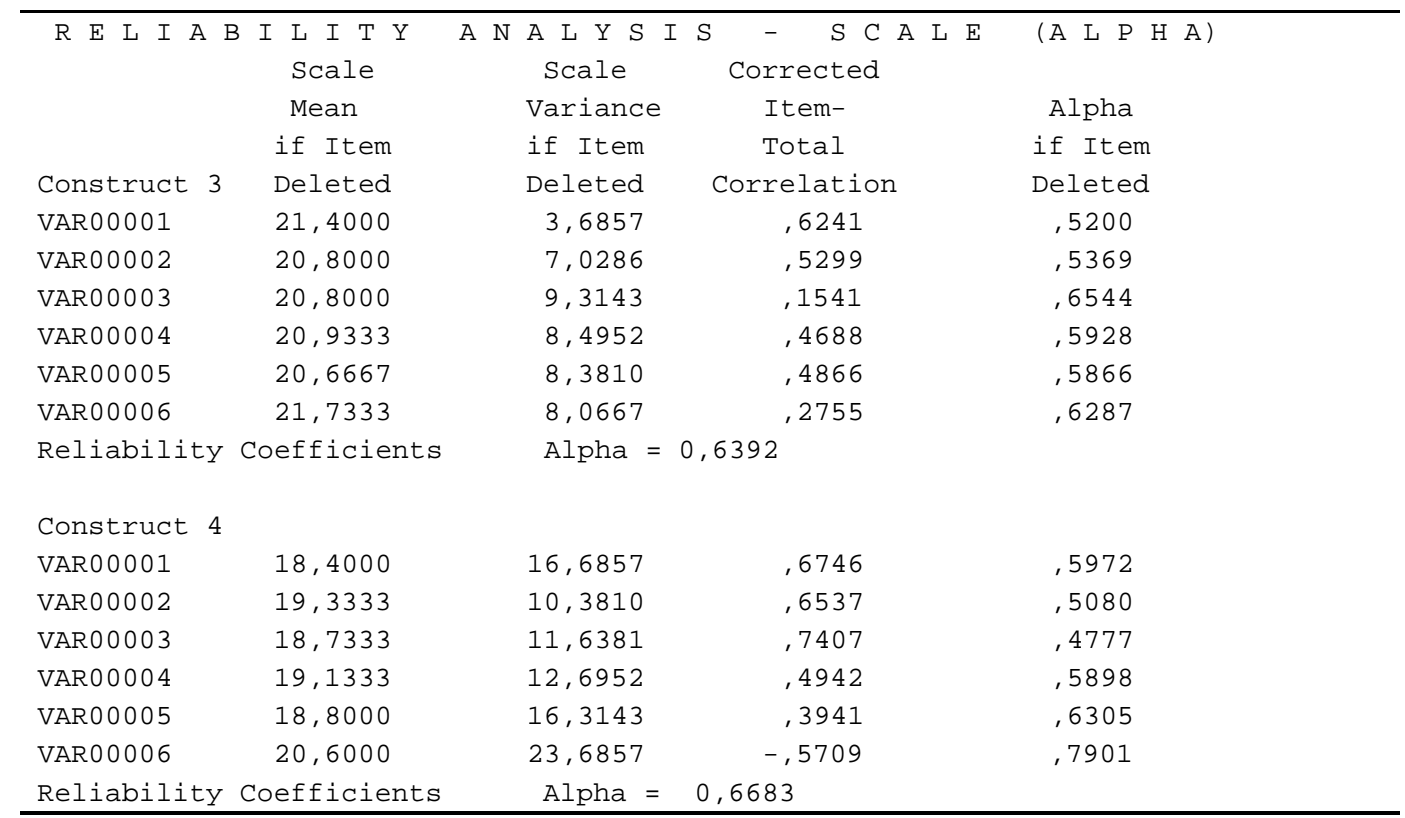

\section{Discussão dos resultados}

A seguir são discutidos aspectos relevantes observados no decorrer do processo e que podem motivar reflexões e avanços na metodologia. Como o uso dos coeficientes ponderados não alterou o resultado, será analisado apenas o resultado obtido com os coeficientes unitários.

A metodologia proposta limita-se a fenômenos descritos por estruturas arborescentes (treelike), que podem ser analisados por técnicas matemáticas relativamente simples.

Uma dificuldade surgiu na construção da Tabela 2: como garantir que as variáveis indicadas fossem mutuamente exclusivas. Conforme Hogart (1988), em uma abordagem científica é muito difícil encontrar construtos totalmente exclusivos. Também Saaty (1991) afirma que, na compreensão humana da natureza, é possível encontrar alguma inconsistência, que se reflete em alguma perda de exclusividade nos construtos. Portanto, alguma zona de sombreamento deve ser esperada entre os campos de ação das variáveis, desde que essa zona não prejudique a análise como um todo. Feita essa ressalva, o uso de variáveis categóricas para representar as variáveis manifestas que sustentam os construtos mostrou-se satisfatório. O uso de questionários e da escala de Likert para a verificação de variáveis também se mostrou satisfatório, já que a confiabilidade medida pelo alfa de Crombach conseguiu separar construtos de alta e de baixa confiabilidade e, dentro destes, as perguntas que mais suscitaram dúvidas. Os valores de 0,64 e 0,67 não parecem comprometer a investigação, estando próximos dos valores aceitáveis. Um dos objetivos da pesquisa era exatamente explicitar o nível de entendimento dos respondentes acerca do termo teórico, portanto, também o alfa de Crombach pode ser usado como indicador de conhecimento dos construtos investigados.

Pelo método K-means otimizado dividiram-se as observações em três aglomerados: compreensão fraca, média e forte. Preferiu-se usar as somas dos construtos, pois as 30 perguntas individuais tiveram pouco poder de discriminação: um dos aglomerados resultou em apenas uma observação. Remete-se à continuidade das pesquisas a investigação das características das empresas agrupadas que resultará na descrição dos aglomerados.

Apresentam-se as empresas classificadas nos três aglomerados e as distâncias euclidianas dos casos até os centros dos aglomerados na Tabela 6. As distâncias finais entre os centros dos aglomerados são apresentadas na Tabela 7 .

O papel da teoria na construção do modelo foi decisivo. Sem a fundamentação teórica deduzida racionalmente talvez não se chegasse às variáveis manifestas escolhidas. As variáveis medidas mostraram-se adequadas ao objetivo da pesquisa, pois foi possível discriminar os respondentes ao longo de ampla faixa de conhecimento, de 37\% a 88\%. Não foi possível rejeitar a hipótese de que os 15 valores de compreensão pertençam a uma distribuição normal, com média de $66,54 \%$ e desviopadrão de 14,47. O menor nível de significância de testes foi 0,25, obtido no teste do qui-quadrado (fonte: software ProConf 98). A classificação por aglomerados também se mostrou satisfatória, mesmo sendo preciso classificar os respondentes pelas somas dos construtos, pois a classificação pelas perguntas foi pouco discriminatória. Essa restrição não parece comprometer a análise, uma vez que os construtos são a verdadeira base da teoria apresentada para o termo teórico e, a partir dessa base, conseguiu-se uma classificação suficiente em respondentes fortes, médios e fracos. 
Um ponto que pode ser explorado é o alinhamento entre a proposta deste trabalho e os métodos de medição de desempenho apontados, pois estes se propõem a medir um termo teórico e, portanto, intangível. O objetivo principal desses métodos é organizar e racionalizar a medição empresarial no apoio à gestão, e não modelar analiticamente as grandezas mensuradas. Ainda assim, algum avanço é possível. O modelo Quantum e o BSC medem o termo "gestão estratégica", enquanto os modelos baseados no prêmio Malcolm Baldridge medem o termo "gestão pela qualidade". O modelo Quantum divide o termo teórico em três construtos, mensuráveis em três camadas. Aplicações do modelo provavelmente geram medições com altas correlações, já que não há nenhuma prevenção em sua construção. No entanto, a estrutura final das medições pode ser rearranjada, resultando em uma estrutura arborescente. Ao mensurar a seqüência de execução de uma estratégia, o BSC assume uma estrutura de fila, pois a perspectiva financeira se apóia nos clientes que, por sua vez, se apóiam nos processos internos, que, finalmente, se apóiam na perspectiva de aprendizado. Se o termo teórico é suportado por mais de um tipo de cliente, suportados por mais de um processo interno e por mais de um tipo de aprendizado, a estrutura de fila também se torna arborescente, mesmo tolerando interferências mútuas. Speckbacher et al. (2003) apresentam casos de uso do BSC que se assemelham mais a uma estrutura arborescente, associando essas aplicações aos escritos iniciais dos autores, quando a própria idéia do BSC ainda não era clara. Já o prêmio Malcolm Baldridge divide o termo teórico em sete construtos e dezenove variáveis medidas categoricamente. $\mathrm{O}$ valor final do modelo é uma combinação linear das medições das variáveis, ponderadas pelos coeficientes das próprias variáveis e dos construtos, em uma estrutura arborescente. Uma contradição emerge e deve ser tratada, já que o próprio modelo se apresenta como uma estrutura circular entre construtos. De Lamare et al. (2001) modelaram com equações estruturais essa estrutura circular de implementação de um modelo de gestão baseado no PNQ em uma organização pública brasileira.

Conclui-se que as estruturas dos três modelos podem ser deduzidas teoricamente pelo uso do modelo ora proposto para a medição de conceitos intangíveis, desde que haja procedimentos que previnam ou ao menos minorem a perda da mútua exclusividade. Uma decorrência imediata do método proposto é a possibilidade de se flexibilizarem os valores e os temas dos construtos e as variáveis do prêmio Malcolm Baldridge, atribuírem-se pesos às perspectivas do BSC ou ainda introduzirem-se ponderações aos construtos do modelo Quantum sempre que o ambiente e o objetivo estratégico da organização variar.

Tabela 5 - Análise de aglomerados para os casos observados. Fonte: software SPSS, v. 8.0.0.

\begin{tabular}{|c|c|c|c|c|c|c|c|c|}
\hline 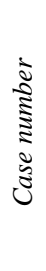 & $\begin{array}{l}\text { :ี } \\
\text { ڤ }\end{array}$ & 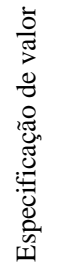 & 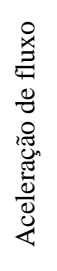 & 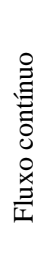 & 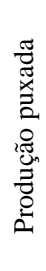 & 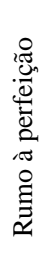 & 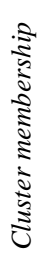 & 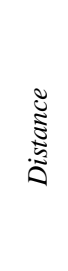 \\
\hline 1 & 135 & 27 & 23 & 27 & 29 & 29 & 1 & 3,0 \\
\hline 2 & 130 & 25 & 23 & 27 & 27 & 28 & 1 & 4,7 \\
\hline 3 & 124 & 23 & 24 & 26 & 25 & 26 & 1 & 7,6 \\
\hline 4 & 118 & 26 & 19 & 25 & 25 & 23 & 1 & 8,1 \\
\hline 5 & 107 & 23 & 18 & 25 & 23 & 18 & 2 & 12,6 \\
\hline 6 & 133 & 26 & 23 & 26 & 30 & 28 & 1 & 3,9 \\
\hline 7 & 119 & 25 & 21 & 22 & 27 & 24 & 1 & 8,3 \\
\hline 8 & 78 & 25 & 8 & 17 & 22 & 6 & 3 & 0,0 \\
\hline 9 & 98 & 14 & 20 & 18 & 23 & 23 & 2 & 0,0 \\
\hline 10 & 136 & 29 & 23 & 28 & 29 & 27 & 1 & 0,0 \\
\hline 11 & 79 & 22 & 15 & 13 & 20 & 9 & 3 & 9,3 \\
\hline 12 & 114 & 25 & 21 & 20 & 25 & 23 & 1 & 10,8 \\
\hline 13 & 96 & 21 & 12 & 19 & 28 & 16 & 3 & 13,1 \\
\hline 14 & 75 & 16 & 6 & 26 & 20 & 7 & 3 & 13,1 \\
\hline 15 & 106 & 16 & 12 & 26 & 26 & 26 & 2 & 12,2 \\
\hline
\end{tabular}


Tabela 6 - Distâncias entre os centros finais dos aglomerados. Fonte: software SPSS, v. 8.0.0.

\begin{tabular}{cccc}
\hline \multicolumn{4}{c}{ Distances } \\
\hline Cluster & 1 & 2 & 3 \\
1 & & 11,084 & 22,313 \\
2 & 11,084 & & 15,404 \\
3 & 22,313 & 15,404 & \\
\hline
\end{tabular}

\section{Conclusões e sugestões para trabalhos futuros}

Comparando-se os resultados, pode-se considerar que os objetivos foram alcançados. A classificação obtida e a confiabilidade foram satisfatórias e o escalonamento e a distribuição entre os respondentes quanto à compreensão do termo teórico proposto foram representativos. Portanto, a metodologia proposta pode ser usada em medições de valores intangíveis, segundo os pressupostos atuais.

Como continuidade do trabalho são apresentadas algumas alternativas.

Para novas aplicações da mesma metodologia, sugerese a modificação das perguntas apontadas como suscitadoras de dúvidas. Para a indústria ora investigada, considerando a classificação em forte, médio e fraco, sugere-se um aprofundamento da pesquisa, desta vez sob um enfoque qualitativo. Propõe-se a condução de um estudo em grupo focalizado em uma empresa de cada aglomerado, em que poderiam ser investigados os modelos mentais ou as principais crenças que determinaram a classificação obtida. Sugere-se ainda uma extensão da pesquisa qualitativa a empresas correlatas, como uma operadora de destaque nacional, e ao menos uma empresa representante da cadeia de valor, fornecedora de serviços de manutenção e autopeças. A participação da entidade de classe da indústria também é representativa e deverá ser incluída na extensão qualitativa. O objetivo dessa extensão será construir uma forma de apresentar a idéia da mentalidade enxuta, maximizando a chance de aceitação para o conjunto das empresas participantes da pesquisa.
Sugere-se abrir uma linha de pesquisa para aplicações que não disponham de uma teoria completa. Uma opção seria a avaliação de $\mathrm{N}$ especialistas, que dariam uma nota empírica global para o termo teórico em estudo e notas parciais para construtos candidatos a entrar no modelo. As avaliações dos especialistas podem ser categóricas. As notas e as medições de variáveis candidatas de M empresas formam um conjunto de ( $\mathrm{N} \times \mathrm{M})$ observações, que devem ser suficientes para a determinação de coeficientes para a indústria por meio da regressão múltipla. Essa regressão indicaria diversos modelos candidatos, sem descartar eventuais interações, selecionáveis conforme os critérios já apresentados. $\mathrm{O}$ modelo selecionado poderá ser usado na medição do mesmo conceito intangível em outros indivíduos da mesma indústria ou de indústrias similares, desde que a transferência do modelo seja aceitável.

Em razão dessa alternativa de continuidade, decidiu-se manter a regressão múltipla na revisão bibliográfica, mesmo que não tenha sido usada especificamente no caso em estudo.

\section{Agradecimentos}

Os autores agradecem às quinze empresas que responderam aos questionários e a sua entidade de classe, a Associação de Transportadores de Passageiros de Porto Alegre (ATP). As conclusões e as possíveis implicações deste trabalho e de suas continuidades estão disponíveis para essas organizações. Agradecem também o suporte do CNPq e da UNISINOS fornecido por meio da concessão de bolsas de pesquisa. Agradecem ainda aos revisores anônimos pelas contribuições que permitiram melhorar a qualidade do material apresentado.

\section{Referências Bibliográficas}

BARROS, A.; LEHFELD, N. Fundamentos de metodologia científica. São Paulo: Makron Books do Brasil, 2000.

BNQP. Criteria for performance excelence. Disponível em: http://www.quality.nist.gov/Business_Criteria.htm. Acesso em: nov. 2003.

BITITCI, U. Modelling of performance measurement systems in manufacturing enterprises. Int. J. Production Economics, Elsevier Science B.V., v. 42, p. 137-147, 1995.
De LAMARE, S. et al. Avaliação da implementação das práticas-chave de melhoria da qualidade em organizações públicas: aplicações ao Instituto Militar de Engenharia. Instituto Militar de Engenharia, Departamento de Engenharia de Sistemas, Relatório técnico n. 66/DE9/01. Disponível em: http://www.ipanema.ime.eb.br/RelTec/2001/Rt068-01.PDF. Acesso em: dez. 2002.

DRAPER, N.; SMITH, H. Applied regression analysis. N. York: John Wiley \& Sons, 1981. 
ENSSLIN, L et al. Apoio à decisão. Florianópolis: Ed. Insular, 2001.

FRENCH, S. Decision theory: an introduction to the mathematics of rationality. Chichester, West Sussex, UK: Ed. Ellis Horwood, 1986

HAIR, J. et al. Multivariate data analysis. New Jersey: Prentice Hall, 1998.

HOGART, R. Judgement and choice. Essex, UK: John Wiley \& Sons, 1988

HRONEC, S. Vital signs - using quality, time, and cost performance measurements to chart your company's future. Arthur Andersen Co., 1993.

LAKATOS, E.; MARCONI, M. Metodologia científica. S. Paulo: Ed. Atlas, 1991.

PAPOULIS, A. Probability, random variables and stochastic processes. Singapore: McGraw-Hill International, 1984.
PEREIRA, J. Análise de dados qualitativos. São Paulo: Edusp, 1999.

SAATY, T. Método de análise hierárquica. São Paulo: Makron Books do Brasil, 1991.

SOHN et al. Corporate strategies, environmental forces and performance measures: a weighting decision support system using the k-nearest neighbor technique. Expert Systems with Applications, v. 25, p. 279-292, 2003.

SOUZA FILHO, D. Iniciação à história da filosofia. Rio Janeiro: Jorge Zahar ed., 2000.

SPECKBACHER, G. et al. A descriptive analysis on the implementation of Balanced Scorecards in german-speaking countries. Management Accounting Research, v. 14, p. 361887, Academic Press, 2003.

WOMACK, J.; JONES, D. A mentalidade enxuta nas empresas. Rio de Janeiro: Campus, 1997.

\title{
AN APPROACH FOR MEASUREMENT OF INTANGIBLE VALUES IN PRODUCTION SYSTEMS
}

\begin{abstract}
This paper describes the development and application of a method for developing measurements for intangible values in productive systems. Nowadays, mainly in service organizations, intangible values are been used for modeling phenomena, understanding problems, proposing and implementing strategies. From concepts presented in the measurements theory, the philosophy of science and multivariate statistics, an approach for modeling theoretic terms relevant to productive systems is developed. The approach comprises a theoretical mapping of non-manifested variables, definition of constructs, definition of state variables, which can be related to intermediate concepts and supporting manifested variables, which can assume categorical formats, assessed by appropriate techniques like questionnaires. After the definitions, one can represent the focused phenomenon by a path-diagram. If the diagram takes a treelike form, multiple regressions may be used and the mathematical formulation becomes easier. If the diagram takes a systemic form, including circular relationships, a more complex mathematical treatment is required, escaping from the scope of this paper. The proposed approach is illustrated through a case study where the capacity of understanding the Lean Thinking concept was assessed in fifteen passengers transportation companies from Porto Alegre, Brazil. The results are discussed and suggestions for the continuity of the research are presented.
\end{abstract}

Key words: intangible values measurements, theoretical terms modeling, categorical data, lean production. 